\title{
Twin Pregnancy with Fetus Papyraceous
}

\author{
Upadhyaya I,' Pradhan M,' Sharma R' \\ 'Paropakar Maternity and Women's Hospital, Thapathali, Kathmandu, Nepal.
}

\begin{abstract}
A successful pregnancy outcome with vaginal delivery of a term single live fetus in case of twin pregnancy with other twin papyraceous, (vanished in second trimester) is an uncommon finding. Ten percent of all perinatal deaths are related with dizygotic twins. The rate of intrauterine fetal demise in multiple pregnancies is as high as three times of monozygotic. Most frequently used and suggested method is follow-up of the maternal coagulation system by a series of lab test. Sonography is a visual tool to confirm the diagnosis. In case of monofetal death of twin pregnancies, the type of placenta should be analysed and then follow up and treatment modalities of these cases should be choosen
\end{abstract}

Key Words: death, fetal, pregnancy, single, twin

\section{INTRODUCTION}

In a multiple pregnancy a dead fetus becoming papyraceous and the surviving fetus growing normally is not a common event. Multiple gestations are now estimated to occur in $12 \%$ of all spontaneous conception but only $14 \%$ of these survive to term. ${ }^{1}$ Incidence of fetus papyraceous in twin is 1 in 12,500. Fetus papyraceous or compresses results when a fetus dies in utero early (usually in early second trimester between 15-20 weeks) and is not expelled out, resulting in its atrophy and mummification. ${ }^{2}$ Here, we present a case of twin pregnancy of singleton normal fetus with papyraceous.

\section{CASE REPORT}

A 26 year female $\left(G_{4} P_{2} L_{2} A_{1}\right)$ with amnorrhoea for five months was large for fundal height than the gestational age. Trans abdominal scan revealed single sac, live twin fetus first cephalic and second breech presentation biparital diameter and femoral length corresponding to
22 weeks gestational age with single anterior uterine wall placenta with normal liquor volume for that gestational age (Figure 1,2). There is no history of ovulation induction, no family history of multiple pregnancy or child with congenital abnormality. Earlier she had induced abortion at ten weeks pregnancy. She was on regular follow up and serial scan revealed normal fetal growth. About 10 weeks later ultrasonography at 32 weeks showed a live fetus with cephalic presentation corresponding to gestational age with estimated fetal weight $1.8 \mathrm{Kg}$, while another fetus was revealed dead measured only 24 weeks size pregnancy high up to continue to the left and liquor of $16 \mathrm{~cm}$. Every two weekly followed up and coagulation profile done to detect disseminated intra vascular coagulopathy was normal. Good counseling was done in each antenatal visit as she used to question "Dead baby would not poison me and live baby in utero". Patient went in spontaneous labour by 38 weeks six days of gestation and delivered vaginally 3025 gms female baby with Apgar score of $6 / 10$ and $9 / 10$ respectively. Following

\footnotetext{
Correspondence:

Dr. Indira Upadhyaya

Paropakar Maternity and Women's Hospital

Thapathali, Kathmandu, Nepal.

Email: indirapu@ntc.net.np,

Phone: $977-9851074598$
} 
which she expelled papyraceous female of 200 gms with shriveled cord (Figure 3). After 10 minutes the placenta was delivered (Figure 4). Injection syntocinon $5 \mathrm{IU}$ bolus and $10 \mathrm{IU}$ was kept in drip. Total blood loss was $150 \mathrm{ml}$ only. Both mother and baby discharged on the second day of puerperium.

\section{DISCUSSION}

Multiple births is associated with a high perinatal morbidity and mortality, double that in singleton pregnancies. ${ }^{4}$ The mortality through the existus of one twin, and major morbidity rate was reported $46 \%$ and etiology can not be strictly detected in numerous cases. Twin pregnancy has the rate of approximately $1: 250$ perinatal morbidity and mortality is increased in these pregnancies. Death of a twin in the first trimester is a frequent event, but it rarely complicates the pregnancy. Despite this, the death of a twin in second or third trimester can cause fetal and maternal complications that can create high risk problems for the perinatalogist in management. ${ }^{5}$

A fetal death in a multiple pregnancy with one or more normally surviving fetus is unusual. This intra uterine accident occurs in 1:184 twin pregnancies $(0.54 \%)$. Incidence of fetus papyraceous in twins is $1: 12,500$.

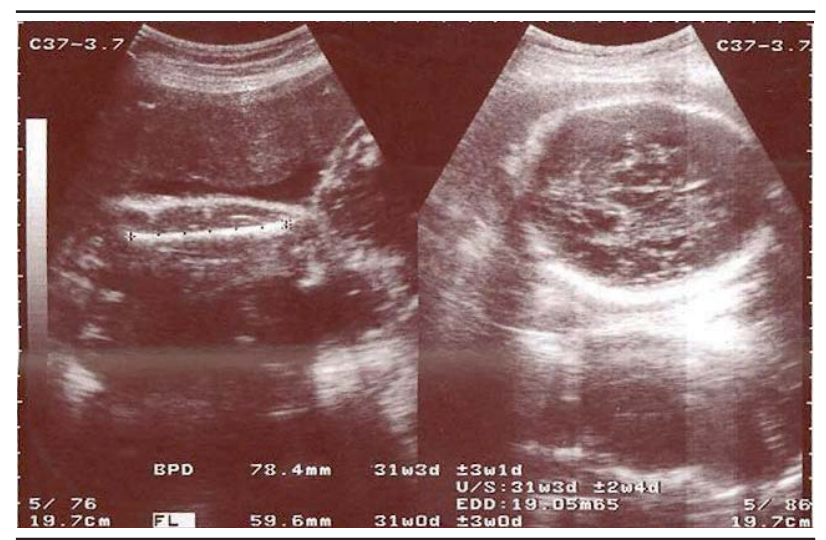

Figure 1. Live fetus at 22 weeks of pregnancy.

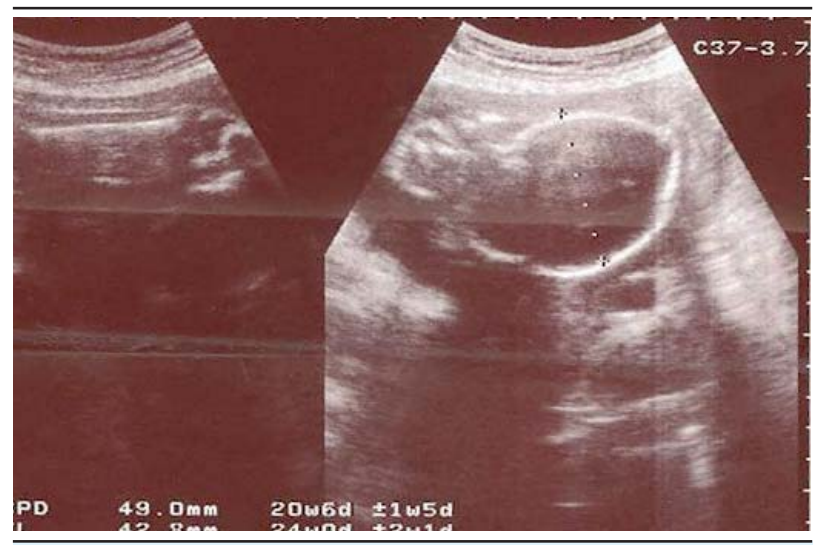

Figure 2. Dead fetus at 32 weeks of pregnancy

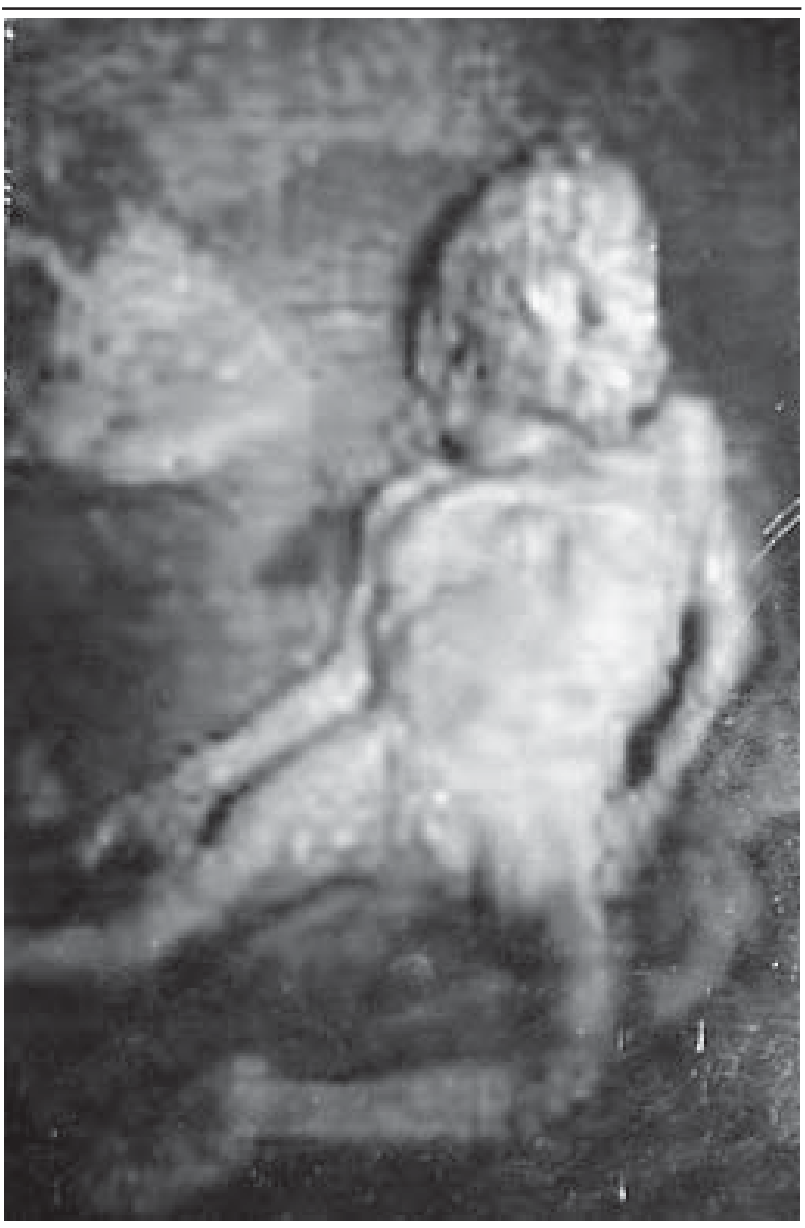

Figure 3. Fetus papyraceous

Fetus papyraceous or compresses results when a fetus dies in utero early (usually in early second trimester between 15 to 16 weeks, where as 32 weeks in this case) and is not expelled out, resulting in its atrophy and mummification. It is a macerated, tiny, fully, formed fetus which is usually dry and papery because the amniotic fluid and fluid content of the dead fetal tissues and of the placental tissue gets absorbed and the dead fetus gets flattened and compressed between the membranes of the living co-twin and the uterine wall. Most of the fluid will get absorbed from the fetus if it is retained more than 8 weeks in utero. ${ }^{6}$ Fetus papyraceous can occur in both uniovular and binovular twins but is more common in uniovular twins. Surviving fetus can have problems due to twin embolization syndrome $25 \% .^{7}$ The musculoskeletal abnormalities found in fetus papyracaous itself may have resulted from prolonged maceration and compression in utero. In our case the lab test results for coagulation system done within the normal limit. If fetus papyraceous is diagnosed antenatally serial evaluation of the surviving fetus by sonography, biophysical profile, dopplor and maternal coagulation factors should be done serially. Zygosity and chorionocity evaluation should be performed antenatally. Death of a binovular twin 
helps the surviving twin. The surviving twin often has the sequelae of twin emobolization syndrome is a complication following in utero demise of the co-twin. It results from the embolization of placental and fetal thromboplastin or necrosed fragments of the dead placenta causing disseminated intravascular coagulation or even ends arteritis. The emboli can predominanetly damage highly vascularized organs such as brain and kidney but can affect all the organs systems. Prevalance of cerebral palsy in surviving twins was over 50 times higher than normal. Study showed extracranial abnormalities include small bowel atresia, gastroschisis, hydrothorax, renal cortical necrosis and aplasia cutis. Study done in 295 twin gestation 12 of them (4.1\%) were complicated by the intrauterine death of one fetus in the third trimester. Maternal coagulation changes did not occur in those cases. All live born infants were without evidence of hematological abnormalities. No specific complications of fetus papyraceous in either mother or the surviving twin are reported in the literature. Other studies indicates that the living fetus is under high morbidity and mortality risk. After the first fetus demise, there is an intrauterine mortality risk at $7.8-20 \%$ for living fetus. In addition, in $28-50 \%$ of liveborn fetuses, central neural system damage at various levels. As in singleton pregnancies, in utero retension of a fetus after its death would trigger problems are intravenous coagulation, neurological and nephrological damage and premature birth. However, the incidence of this complication is very low in case of twin pregnancies. Evidence of hematological abnormalities was not found in none of live fetus. ${ }^{8}$ In this study, the surviving twin was healthy with good birth weight $3025 \mathrm{gm}$ of Apgar score $7 / 10$ and 9/10 respectively. Following which she expelled papyraceous $200 \mathrm{gm}$ female with shriveled cord. There were obvious musculoskeletal abnormalities (Figure 3). The placenta was delivered by control cord traction, it was normal weighed $900 \mathrm{gm}$. Total blood loss was $150 \mathrm{ml}$. Both mother and baby did well postpartum and were discharged on the second day of puerperium.

A fetal death in a multiple pregnancy with one or more normally surviving fetus is unusual. It is important to reassure the patient of the normal outcome expected in most of the cases. The diagnosis of multiple pregnancies is not missed during ultrasound examination. If possible delivery should be scheduled at tertiary center. Good management of labour and thoroughly inspected placenta and membranes will permit the diagnosis of abnormalities of its and of fetus papyraceous as occurred in this case.

\section{REFERENCES}

1. Dwivedi S. A case of vanishing twin. Obs and Gynae today. 2002;7(6):327-8.

2. Woo HHN, Sin SY, Tang LCH. Single fetal death in twin pregnancy. HKMJ. 2000;6(3):293-300.

3. Bobzom DN, Audu BM. Outcome of twin pregnancies in Maiduguri Nigeria. J Obstet Gynaecol 1997 May;17(3):261-3.

4. Mun S, Mizrak T, Taner CE, Derin G, Büyüktosun C. Death of One Fetus in Twin Pregnancy: Report of Four Cases. Perinatal Journal. 2005 Dec;13(4):223-6.
5. Sahin Z, SAHIN HG, Surucu R, Kamaci M. Intrauterine Death of One Twin: Case Report. J Turkish German Gynecol Assoc. 2003; 4(4):63-5.

6. Mittal PS, Khanna M. Two Papyraceous fetuses in a triplet pregnancy. J Obstet Gynaecol India. 2007;57(1):77-8.

7. Enbom JA. Twin Pregnancy with Intrauterine Death of One Twin. Am J Obstet Gynecol. 1985;152:424-9.

8. Malinowski W, Janowski J, Lokociejewiski J, Rozewiski K, Tomala J. Intrauterine death of one twin in the third trimester. Ginekol Pol. 2003;74:135-43. 